\title{
Un tutorial no es un maestro
}

\section{A tutorial is not a teacher}

\author{
Mari Carmen Díez Navarro*
}

Recibido: 2 de junio de 2021 Aceptado: 3 de junio de 2021 Publicado: 27 de julio de 2021

To cite this article: Díez Navarro, M ${ }^{a}$ C. (2021). Un tutorial no es un maestro. Márgenes, Revista de Educación de la Universidad de Málaga, 2 (2), 139-142

DOI: http://dx.doi.org/10.24310/mgnmar.v2i2.12828

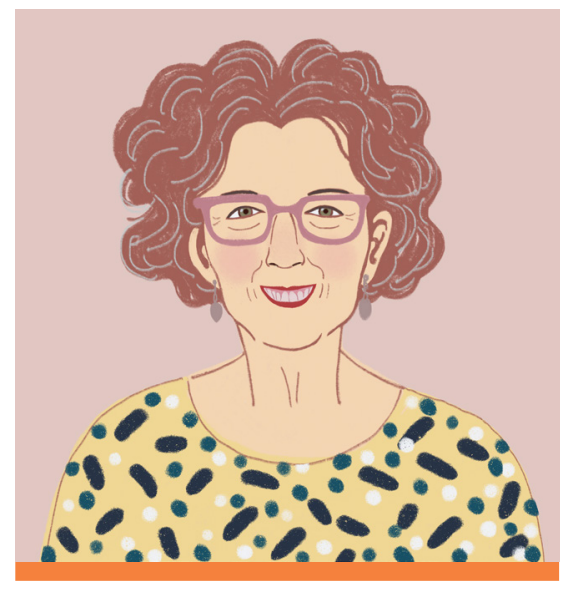

Mari Carmen Díez Navarro

\section{RESUMEN}

En estos días de virtualidad, las pantallas han cobrado un enorme protagonismo, también en la educación. En este contexto de explosión digital que genera tantas adhesiones, la autora nos recuerda que un tutorial no es un maestro y una pantalla no es una escuela.

Palabras clave: virtualidad; pantallas; tutoriales; relación educativa; presencia

\section{ABSTRACT}

Screens have taken on a huge role in these days of virtuality, also in education. In this context in which the digital expansion generates so many supports, the author reminds us that a tutorial is not a teacher and a screen is not a school.

Keywords: virtuality; screens; tutorial; educational relationship; presence

En estos días de virtualidad, de reuniones en las nubes y videollamadas de todo tipo, las pantallas han cobrado un enorme protagonismo para todos. Acudimos a ellas para comunicarnos con otros, para entretenernos, para leer, para mirar, para observar la naturaleza, para curiosear museos, parques y circos, para disfrutar películas, recitales, deportes, espectáculos... También para aprender.

Nuestros niños han estado en este tiempo de encierro recibiendo clases de sus maestros y maestras (que han hecho un gran esfuerzo en ponerse al día en nuevas tecnologías), han buscado información para hacer trabajos a distancia y han 
visto muchísimos tutoriales para averiguar cualquier cosa. Desde cómo se atan los cordones de los zapatos, a cómo se mezcla la pintura para que salga del color que tú quieres; desde cómo se escribe correctamente una palabra a como se hace la prueba del nueve.

Esta explosión digital ha ilusionado y entusiasmado a muchas personas y las ha llevado a sacar la conclusión de que los tutoriales son tan sumamente eficaces e importantísimos, que solo es cuestión de tiempo que las escuelas desaparezcan por completo; ya que de aquí en adelante los niños podrán abastecerse de todos los conocimientos que les sean necesarios, simplemente asomándose a sus ordenadores, tabletas o móviles.

A mi este comentario, que ya he escuchado unas cuantas veces, me parece totalmente injustificado, porque ignora la dimensión humana de la relación educativa entre un maestro y su alumno. Una relación compleja y hermosa, que contiene muchos más matices y elementos a considerar que la simple transmisión de saberes.

Pensemos que los maestros acompañan la evolución de los niños con su presencia implicada y activa, con su actitud de acogida, su escucha, su sensibilidad, su ofrecimiento de las normas y su deseo de que los alumnos crezcan y aprendan lo más saludablemente posible. Pero también acompañan con su trabajo continuado e innovador de cara a mantener viva la curiosidad innata de los niños, a despertar su deseo de saber, a encender la llama del interés por el conocimiento, de tal modo que aprender sea un placer y una búsqueda llevada a cabo por cada cual y por el grupo de compañeros de clase.

Podríamos afirmar además que hay una gran potencia en los vínculos que se crean, esos hilos afectivos que hacen que cada maestro conozca, escuche y comprenda a los niños que tiene a su cargo con un miramiento diferenciado y cuidadoso; poniendo el acento en la diversidad que hay entre ellos, partiendo de sus historias particulares, de sus capacidades, de sus dificultades, de sus identidades en construcción, de sus genuinas subjetividades. Unos vínculos que llevan a los niños a aprender muchas veces para lograr el cariño de sus maestros.

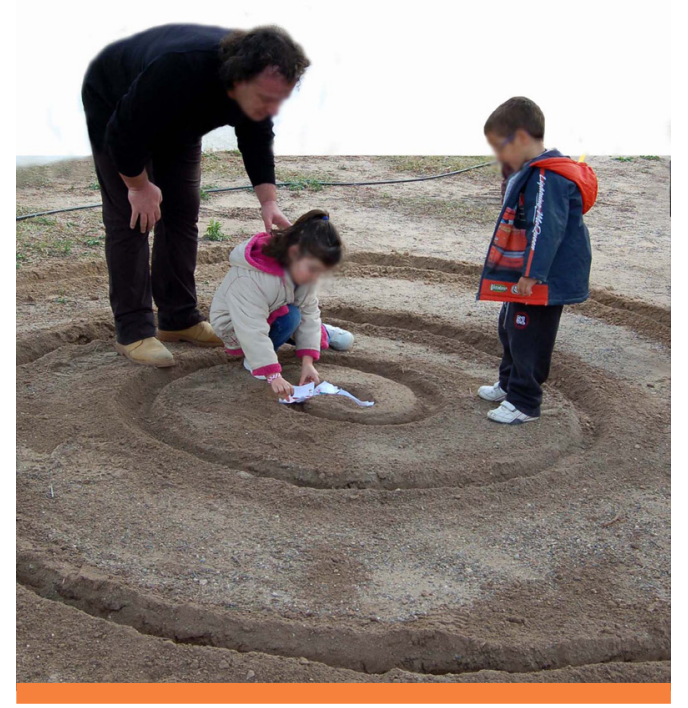

Créditos. Reme Picó. Escuela infantil Aire Libre (Alicante) 


\section{"Enseñar y aprender son verbos muy afectivos."}

De hecho, cuando preguntamos a personas jóvenes o adultas a qué maestros recuerdan más y por qué, las respuestas generalmente van en el sentido de recordar a los maestros que se mostraban más cercanos, que se comunicaban con sus alumnos y les hacían partícipes de alguna de sus aficiones, aventuras o circunstancias vitales. Esos maestros que escuchaban, bromeaban, animaban, cuidaban, se mostraban como personas, y querían a los niños, además de enseñarles.

Ir a la escuela con ganas de que la maestra te mire el pelo recién cortado o las zapatillas nuevas, dice mucho de una relación estrecha, tierna y agradable. Aprenderte las tablas para que tu maestro sonría y te dedique unas cariñosas palabras de valoración, es una parte tan importante del proceso de aprendizaje, como la mejor de las explicaciones teóricas. Con frecuencia vemos que los niños aprenden y trabajan para alegrar a sus maestros, ...o que interrumpen la clase para llamarles la atención. Y es que cada niño necesita tener "algo" con su maestro, una relación particular, afectiva, que le haga sentirse mirado y comprendido por él, un vínculo que le sostenga y le permita tolerar los frenos necesarios, las pequeñas frustraciones cotidianas y las dificultades que vayan surgiendo.

La mirada, la sonrisa y las palabras del maestro se entremezclan con las del niño y conforman una trama afectiva que sustenta el edificio del aprendizaje y crea un ambiente en el que tanto el saber como la relación ocupan un lugar prestigioso y placentero. Nada que ver con el "trato" con un tutorial, medio máquina, medio robot, medio loro. Nada que ver la explicación de una técnica o un procedimiento a base de claridad, orden y repetición, que a base de un buen vínculo afectivo, un ambiente de acogida y un grupo de referencia en el que se puede uno apoyar, ir creciendo y avanzando.

Y es que los tutoriales lo que hacen es recrear la relación educativa tradicional en la que "el que sabe", habla, explica y repite, y "el que no sabe" atiende, escucha e intenta aprender y memorizar los nuevos conocimientos. En este formato no es posible que el aprendiz interactúe con el que realiza la transmisión en un tutorial, ni que se miren o se comuniquen. Lo único posible es ver, escuchar 
y repetir, sin implicaciones afectivas, sin pasión alguna, sin ilusiones ni complicidades.

Si los niños aprendieran mirando tutoriales y no en la escuela con sus maestros, como dicen algunos que quizás llegue a pasar, lo que puede que se acabase no son las escuelas, sino el mismo deseo de aprender. Porque un tu-

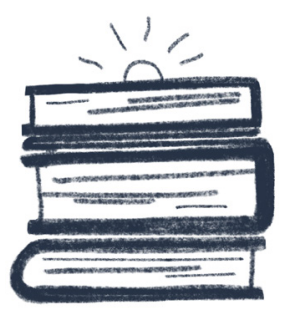
torial no es un maestro y una pantalla no es una escuela.

Enseñar y aprender son verbos muy afectivos. 